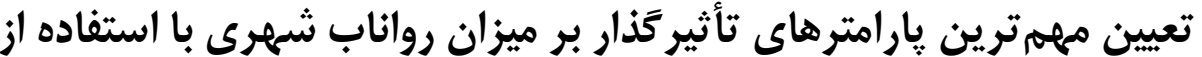

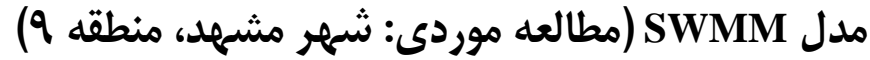

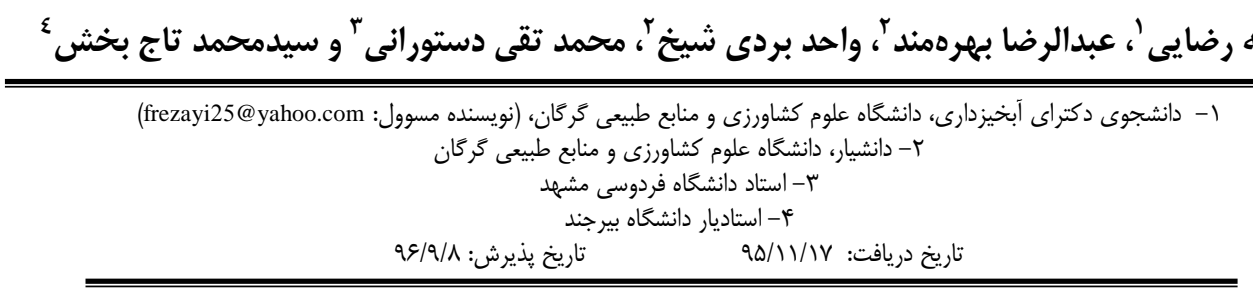

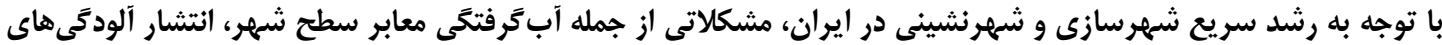

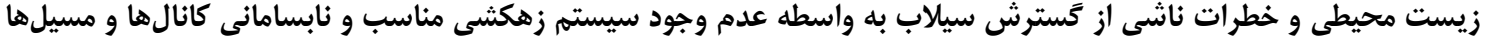

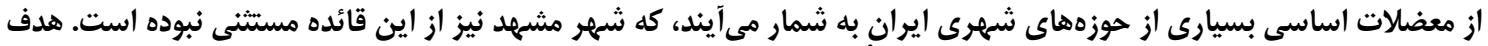

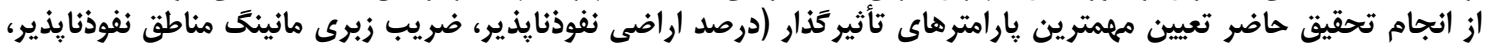

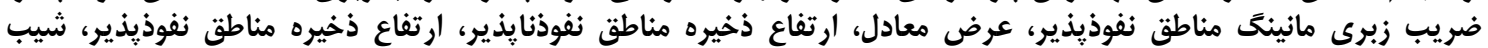

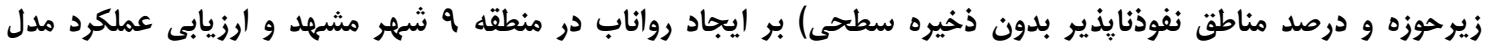

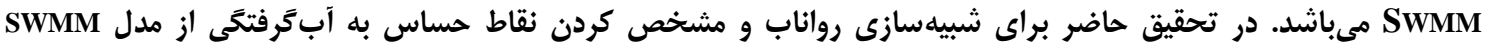

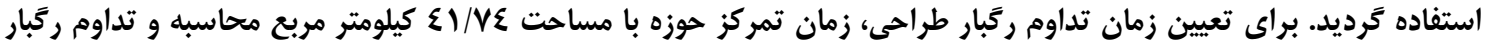

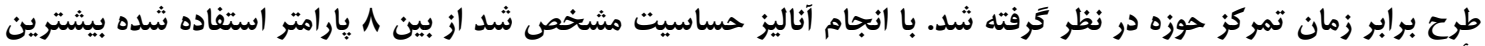

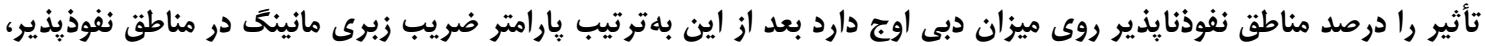

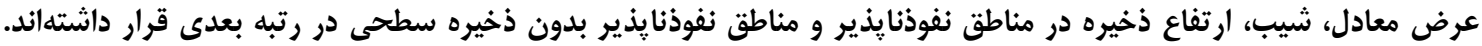

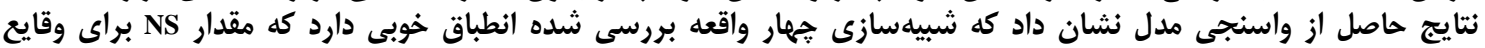

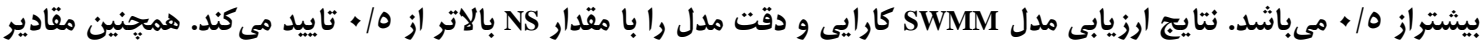

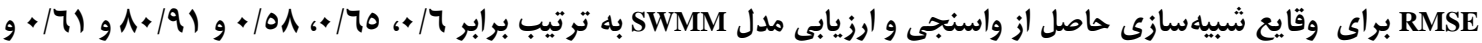

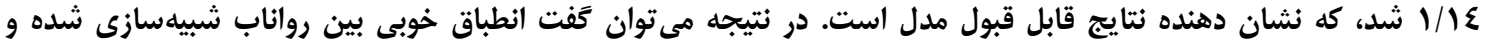

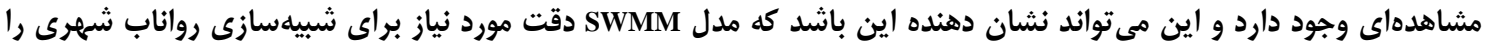

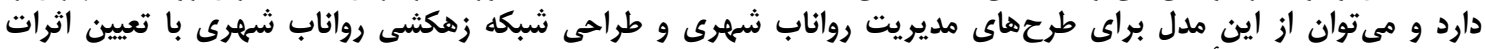

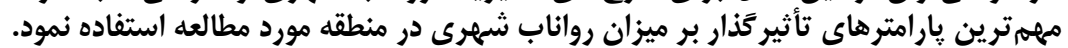

وازههاى كليدى: آناليز حساسيت، ارزيابى مدل، رواناب شهرى، زمان تمر كز، كاليبراسيون، مدل SWMM

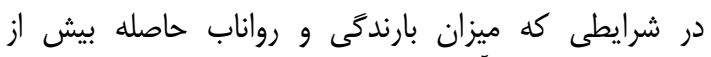

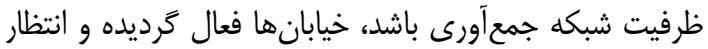

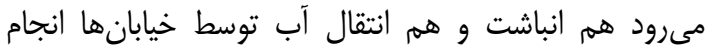

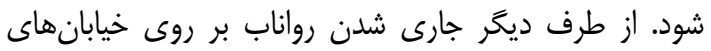

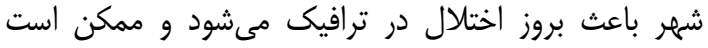

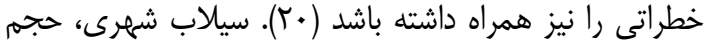

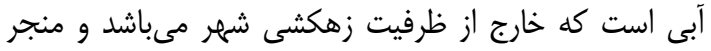

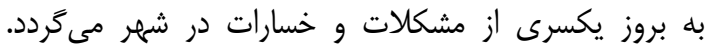

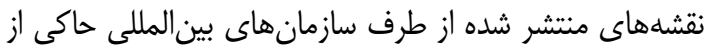

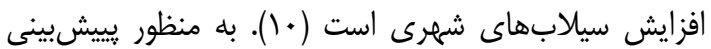

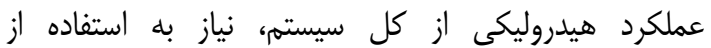

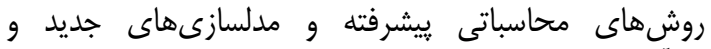

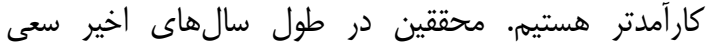

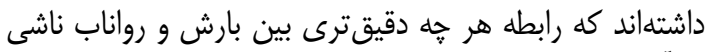

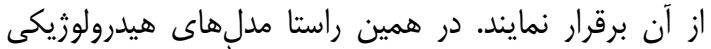

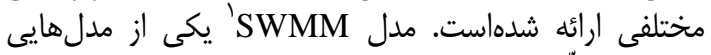

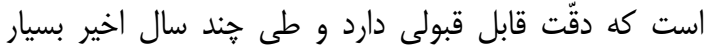

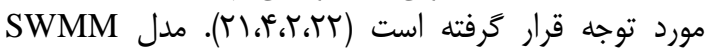

مقدمه

در دنياى امروز ما، كه زندگى شهرى شهرى خسارات جبران

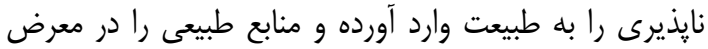

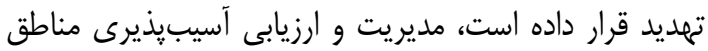

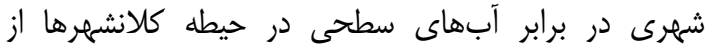

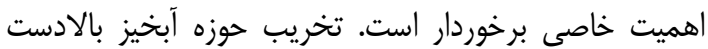

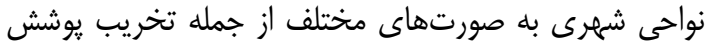

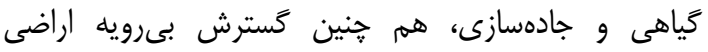

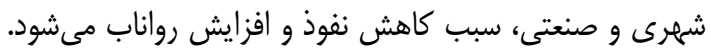

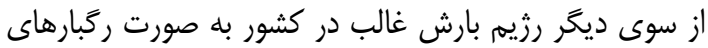

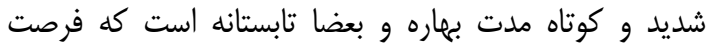

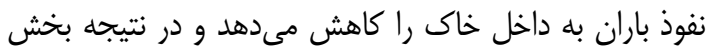

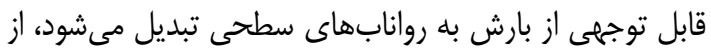

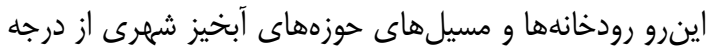

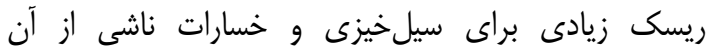

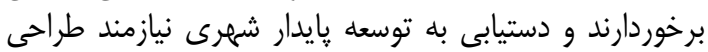

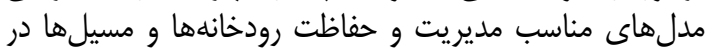

حوزههاى آبخيز شهرى است (19). 
نشان داد. علاوه بر آن مشخص شد كه اين مدل مدل امكان

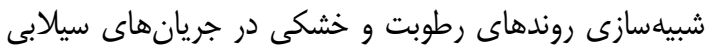

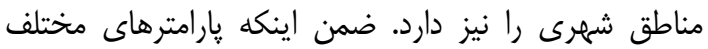

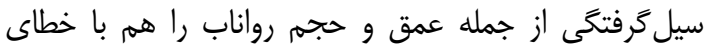
كمى اندازمخيرى مى كن إند.

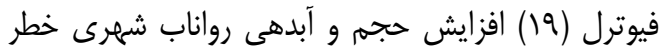

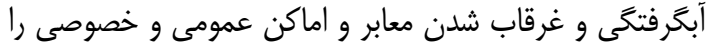

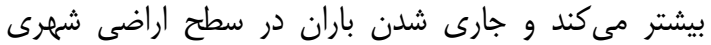

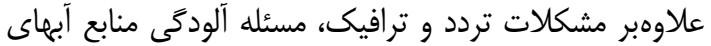
سطحى و زيرزمينى يذيرنده رواناب شهرى ترى را مطرح مى سازدي.

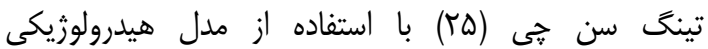

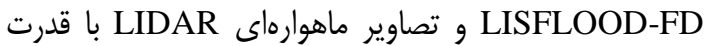

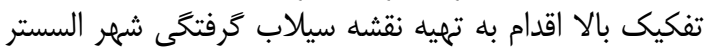

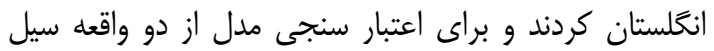

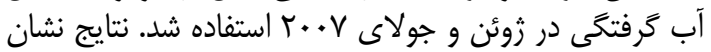

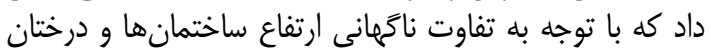

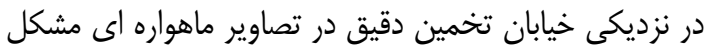

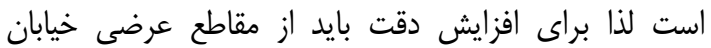

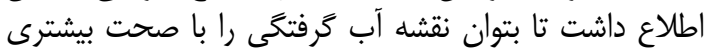

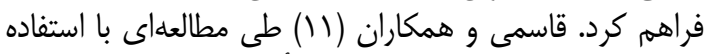

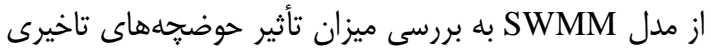
بر كاهش رواناب ترداختند نتايج نشان دادئ داد، استفاده از

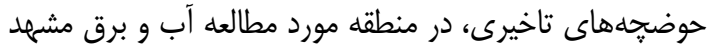

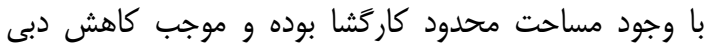

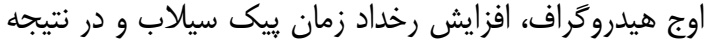

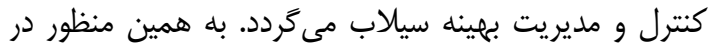

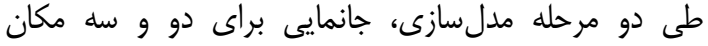

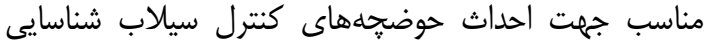

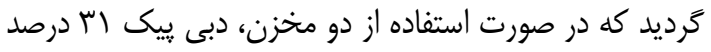

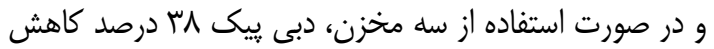

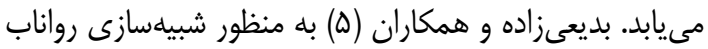

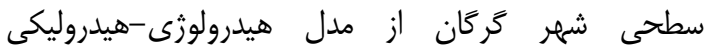

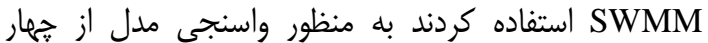

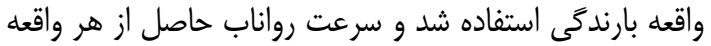

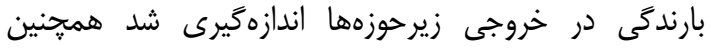

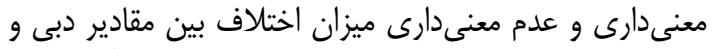

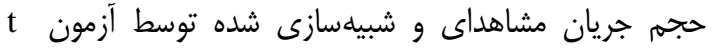

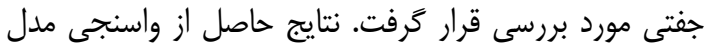

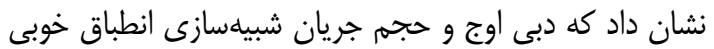

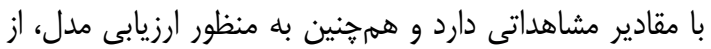

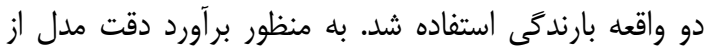
شاخصهاى كارايى مدل شامل NS N

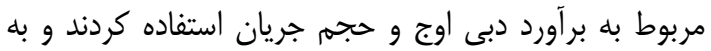

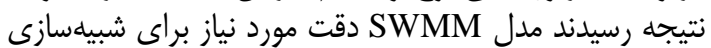

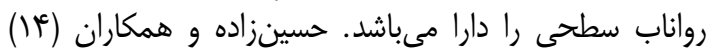

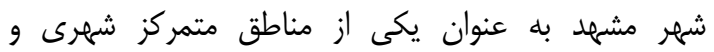

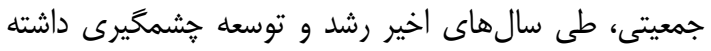

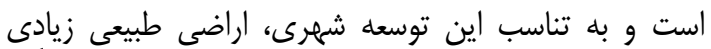
تبديل به سطوح نفوذنايذير شهرى شده است كه متعاقياً با بإي

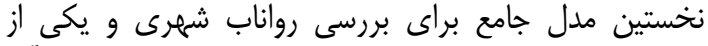

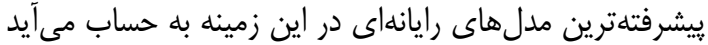

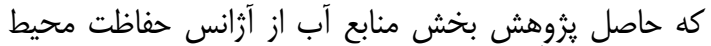

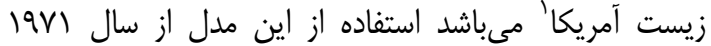

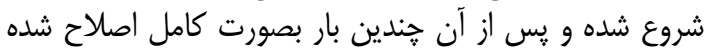

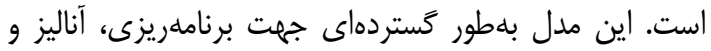

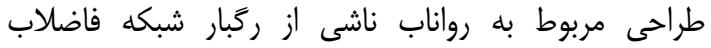

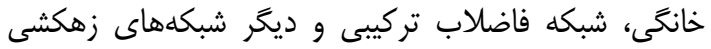

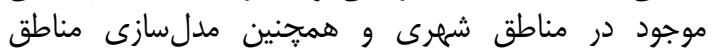
غيرشهرى در سراسر جهان مورد استفاده قرار كرفتنه است.

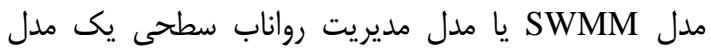

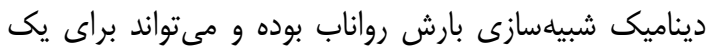

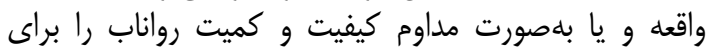

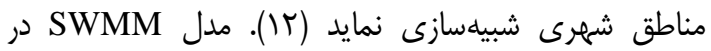

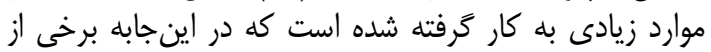
آنها اشاره مى نشود.

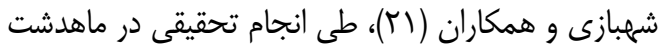

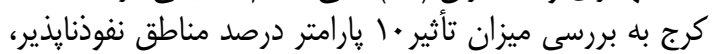

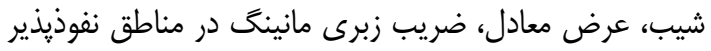

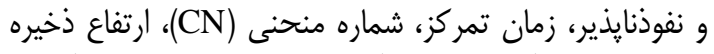

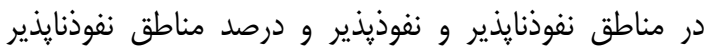

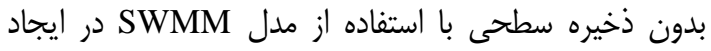

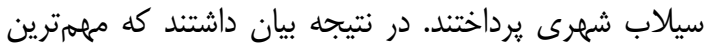

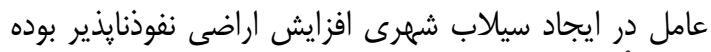

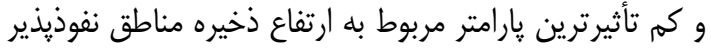

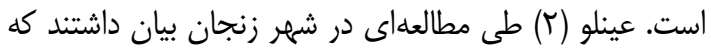

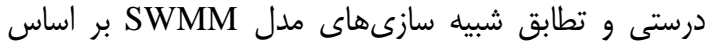

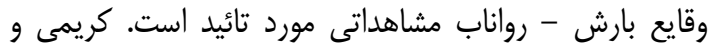

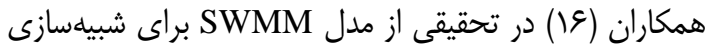

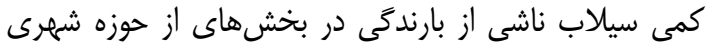

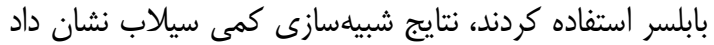

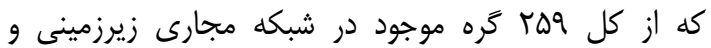

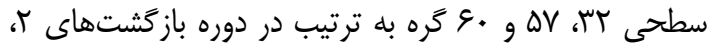

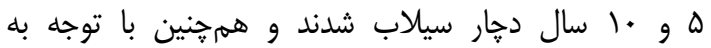

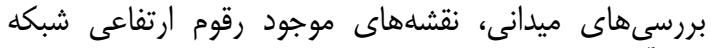

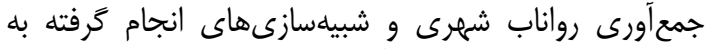

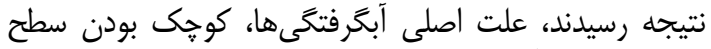

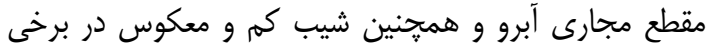

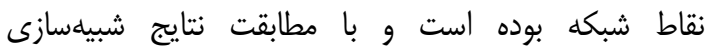

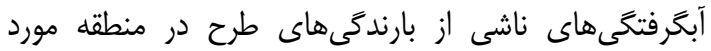

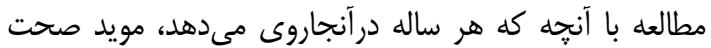
شبيه سازىهاى مدل مى باشدا.

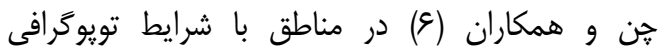

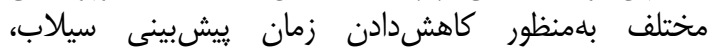

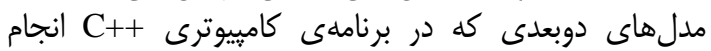

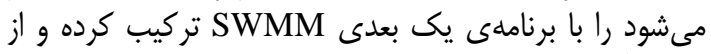

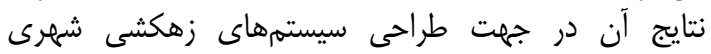
استفاده نمودند. اين تركيب، ظرفيت برايت بالايى را در شرايطى كه

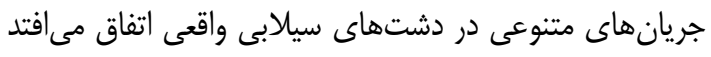




\section{مواد و روشها مور مالعه منطقه مورد مطالعه}

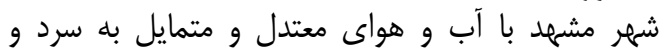
خشك، در شمال شرق ايران واقع شده است و از سمت شت شمال،

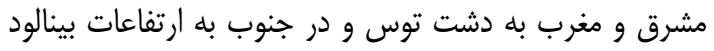

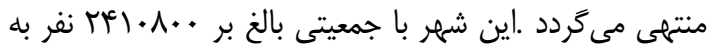

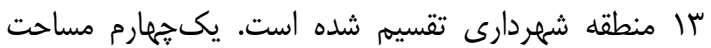

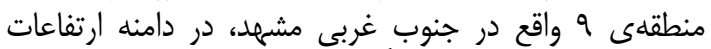

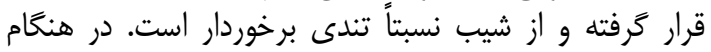

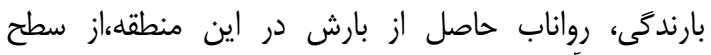

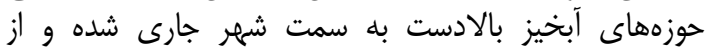

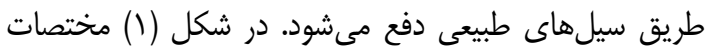
جغرافيايى منطقه مورد مطالعه ارائه شده است.
تغيير در קرخه آبى، ميزان رواناب توليدى از نظر سرعت

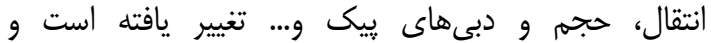

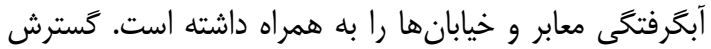

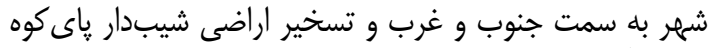

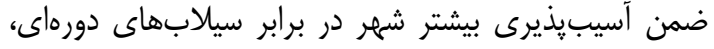

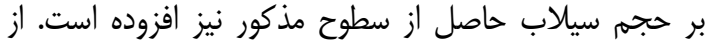

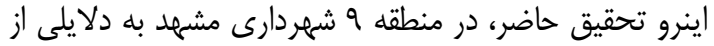

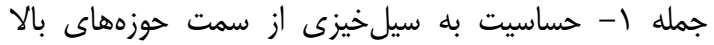

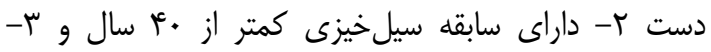

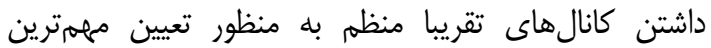

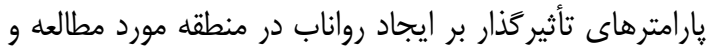

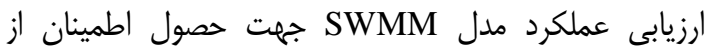
عملكرد مدل ضرورى به نظر مىرسد.

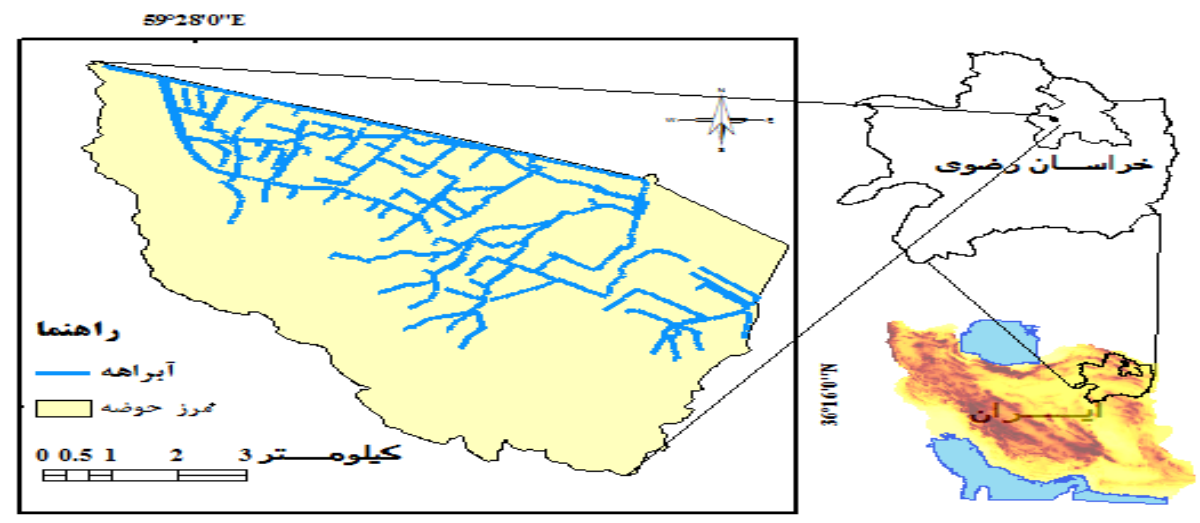

شكل I- نقشه منطقه مورد مطالعه و مرز زير حوزهها

Figure 1. Map of Study Area and Sub Catchment Border

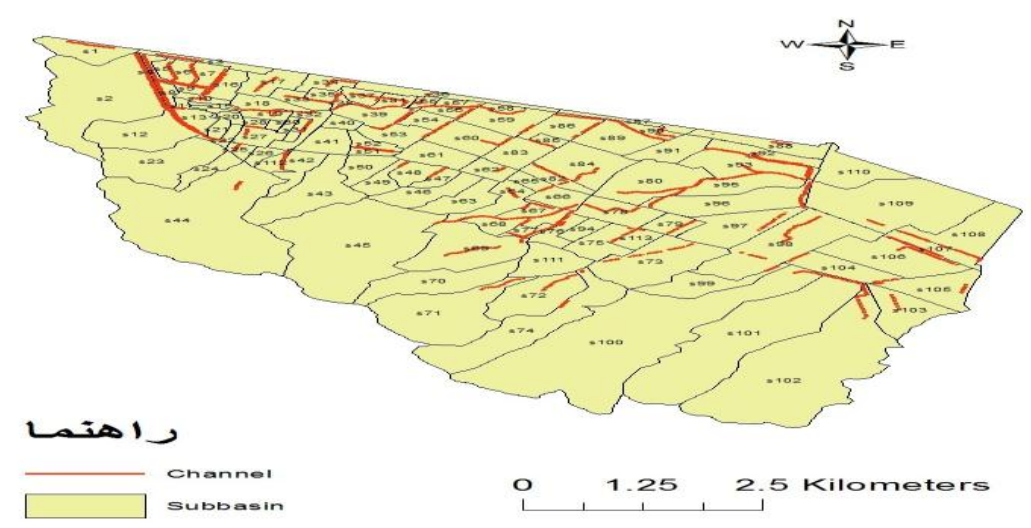

شكل r - نقشه مرز زير حوزهاى منطقله مورد مطالعه و كانالها

Figure 2. Map of Sub Catchment Border and Counduit of Study Area

زهكشى و نقشه بلوكهاى ساختمانى كه از اداره كل راه و

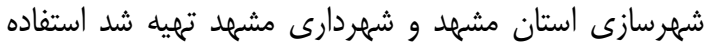

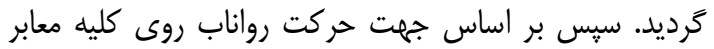

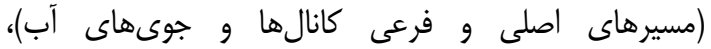

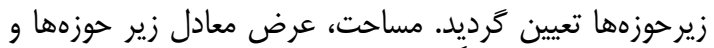
شيب متوسط مستقيماً با استفاده از نرمافزار

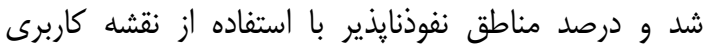
بلدست آمد كه نتايج بدست آمده در جدول بذول (1) ارائه شده است.
دادههاى مورد نياز مدل SWMM: وروديقهاى موردنياز

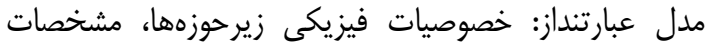
شبكه زهكشى و دادهياى هواشناسى و هيدات فيدرولوزى منى منطقه مورد مطالعه، كه به شرح زير مادير مى هباشند.

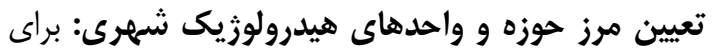

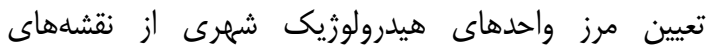

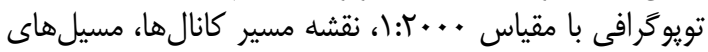


Table 1. The Parameters Calculated Values of Sub Catchment

جدول (- مقادير محاسبه شده پارامترهاى زير حوزهها

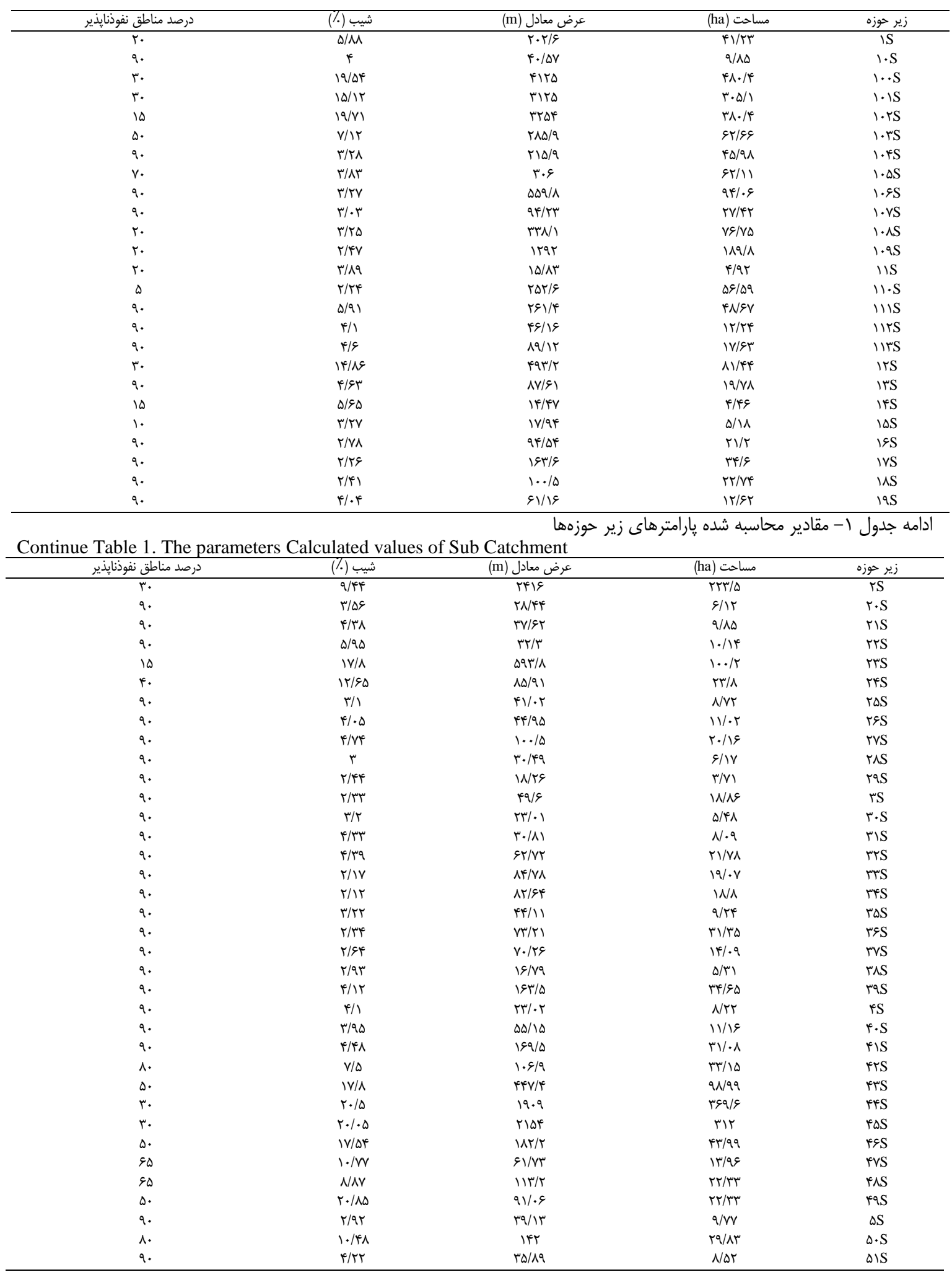


Continue Table 1. The parameters Calculated values of Sub Catchment

\begin{tabular}{|c|c|c|c|c|}
\hline درصد مناطق نفوذنايذير & شيب (.) & عرض معادل (m) & مساحت (ha) & زير حوزه \\
\hline 9 & $r / \kappa \wedge$ & $\Delta r / r q$ & $1 \% / N{ }^{\mu}$ & QTS \\
\hline$q$. & $r / \Lambda r$ & $\mid F T / \Delta$ & $r \cdot / 99$ & QTSS \\
\hline q. & $r / l r$ & $9 . / 4 r$ & $\mid N / T^{\prime} \Delta$ & DrS \\
\hline q. & t/KT & $\Delta \omega / \varnothing \bar{C}$ & $\mid r / 1 Q$ & $\Delta \subsetneq S$ \\
\hline q. & $r / l$ & TF/Tr & $N \cdot r$ & QVS \\
\hline$q$. & $r / 1 \varepsilon$ & $\mu F / \Delta V$ & $V / 19 q$ & $\Delta \wedge S$ \\
\hline$q$. & r/^r & $T V \Delta / 1$ & YN/T & 8.S \\
\hline$q$. & $\mid c / 41$ & $199 / 4$ & $\mathrm{TV} / \Delta T^{\mathrm{C}}$ & 8IS \\
\hline$q$. & $r / 9 \Lambda$ & $1 . r / 4$ & $r \cdot / r$ & grS \\
\hline v. & $\mid 1 / 91$ & $\mathrm{IVq} / \mathrm{V}$ & $<1 / 4 q$ & gres \\
\hline q. & $s(\Delta)$ & $\mid r \Delta / r$ & $r \Delta / 9$ & ges \\
\hline$q$. & r/ar & $91 / 19$ & $\mid w / \cdot V$ & $9 \Delta \mathrm{S}$ \\
\hline$q$. & $r / \cdot \theta$ & 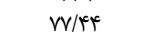 & $18 / 19$ & vS \\
\hline 10 & W/r & $r v q / r$ & $\wedge \mathrm{v} / \mathrm{vq}$ & $v \cdot S$ \\
\hline 10 & TN/IF & IFTD & $109 / c^{c}$ & VIS \\
\hline f. & $11 / r q$ & $\Gamma \wedge \Delta / T$ & $v a / I V$ & vrs \\
\hline 10 & W/AD & $\Lambda \cdot F / 9$ & $1.9 / 9$ & $v^{\sim} S$ \\
\hline 10 & TH/TD & $\Delta V+/ \Delta$ & $\mid Q T / K$ & $v^{e} S$ \\
\hline 9. & $r / \Delta V$ & IVE/A & $r q / \Delta$ & vQS \\
\hline$q$. & L/א & $V N \cdot 9$ & $r I / A r$ & VฯS \\
\hline 9. & سז/ه & 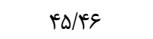 & $1 \mathrm{~W} / \Delta \mathrm{V}$ & vvS \\
\hline 9. & $\Gamma / \Delta 1$ & $T F T / \mu$ & $\leftarrow \Delta / \Delta \wedge$ & VAS \\
\hline$q$. & $r / T V$ & $\mid r \cdot / r$ & $r T / V$ & VaS \\
\hline q. & $r / 91$ & & $q / \wedge \&$ & $\wedge \mathrm{S}$ \\
\hline
\end{tabular}

ادامه جدول ا- مقادير محاسبه شده يارامترهاى زير حوزهها

Continue Table 1. The parameters Calculated values of Sub Catchment

\begin{tabular}{|c|c|c|c|c|}
\hline درصد مناطق نفوذنايذير & شيب (·) & عرض معادل (m) & مساحت (ha) & زير حوزه \\
\hline 9. & $r / \Lambda$ & $F \mid / 10$ & N/HT & $\wedge \Delta \mathrm{S}$ \\
\hline$q$. & ( & $I V D / V$ & ( & $\Lambda \notin S$ \\
\hline q. & T/ץ & MF & $\mid f / V^{c}$ & AVS \\
\hline$q$. & ( & ITw/V & rq/rब & $M S$ \\
\hline$q$. & $r / 11$ & 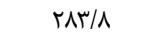 & $p q / q$ & 19S \\
\hline$q$. & $1 / \wedge \Delta$ & re & $V / q$ & १S \\
\hline$q$. & ه ט & $1 \cdots / 1$ & TN/KT & qTS \\
\hline 9. & $r / M$ & r... & $8 F / \Lambda 1$ & $q \mathrm{qu}$ \\
\hline q. & $f / v^{c}$ & $V T / T \Delta$ & ID/MF & 945 \\
\hline$\Delta \Delta$ & $r / \tau$ & $r+/ V$ & 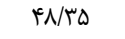 & $9 \Delta \mathrm{S}$ \\
\hline Q. & 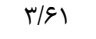 & $F \mid r / g$ & $\Lambda V / D I$ & १९S \\
\hline
\end{tabular}


مورد استفاده مدل هستند. در اين مطالعه شش واقعه رَّبارى براى ارزيابى و واسنجى مدل استفاده شد.

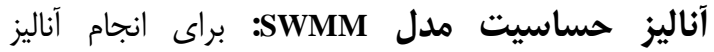

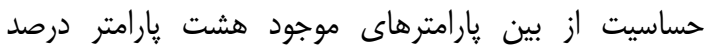

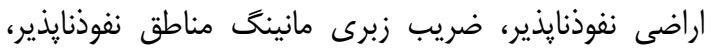

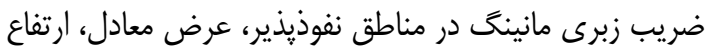

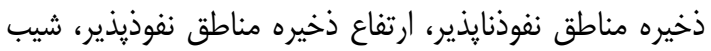

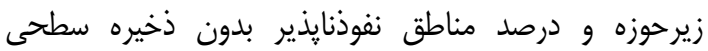

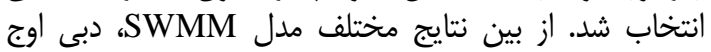

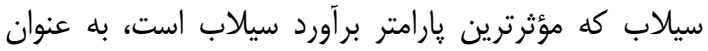

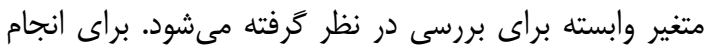

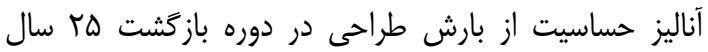

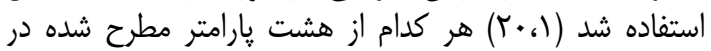

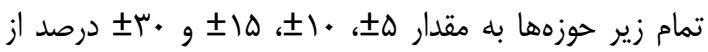

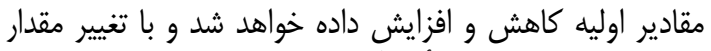

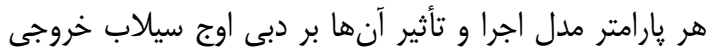

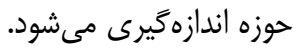

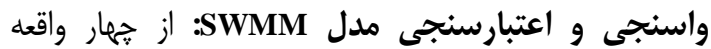
• • • • •

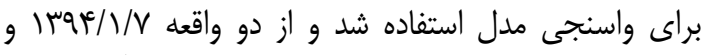

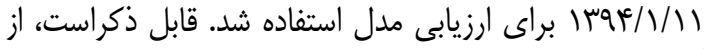

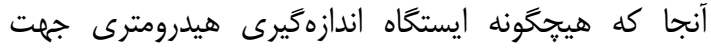

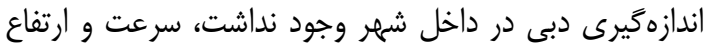

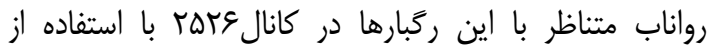

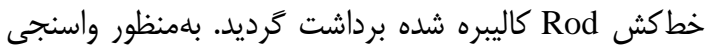

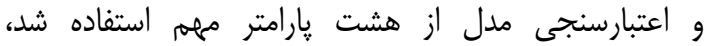

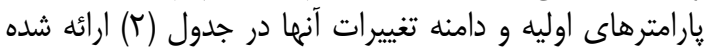

مقادير ضريب زبرى در مناطق نفوذيذير و نفوذنايذير،

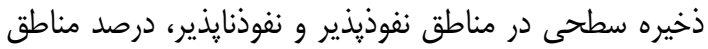

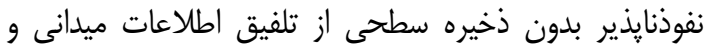
نقشههاى كاربرى در نرمافزار

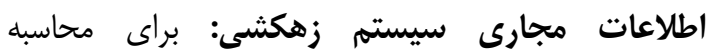

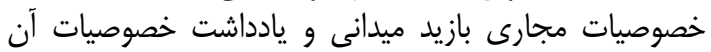

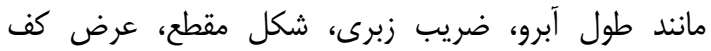

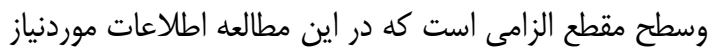

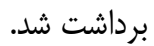
اطلاعات موردنياز اتصالات: مشخصات اتصالات و محل مرات

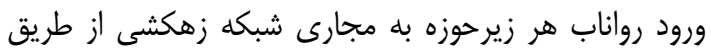

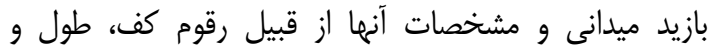

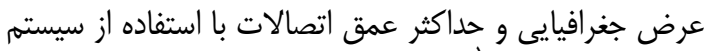

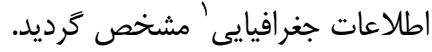

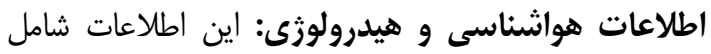

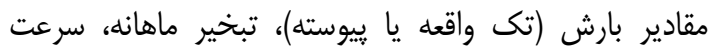

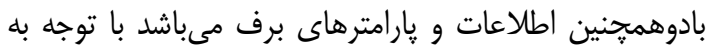

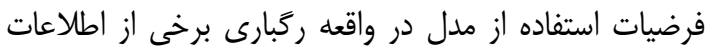

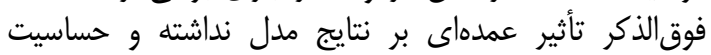

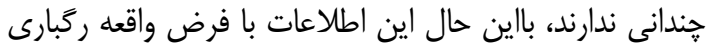

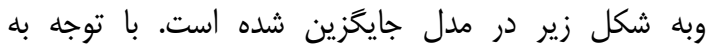

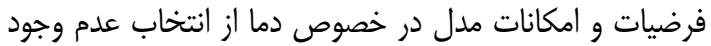

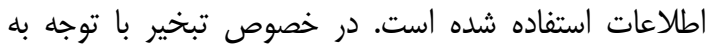

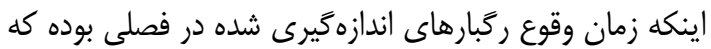

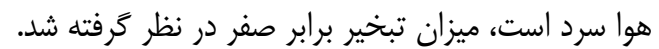

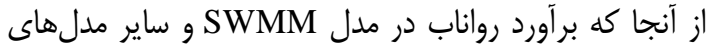

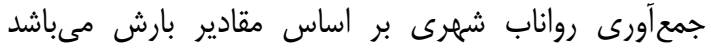

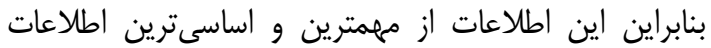

جدول r- مقادير اوليه و دامنه تغييرات قابل قبول متغيرهاى مدل SWMM Table 2- The primary amount and Variation range of the main parameters used in SWMM model

\begin{tabular}{|c|c|c|c|}
\hline منبع & دامنه تغييرات مجاز & مقادير اوليه & متغير \\
\hline Temprano et al (24) & $\pm r$ & - & درصد مناطق نفوذنايذير \\
\hline Temprano et al (24) & \pm r. & - & شيب (\%) \\
\hline Temprano et al (24) & $\pm r$ & - & عرض معادل (متر) \\
\hline Huber and Dickinson (15) & 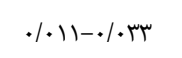 & $.1 \cdot 11$ & ضريب زبرى مانينح مناطق نفوذنايذير \\
\hline Huber and Dickinson (15) & $\cdot / \cdot r-\cdot / \Lambda$ & $\cdot / \cdot \Delta$ & ضريب زبرى مانينَ مناطق نفوذيذير \\
\hline Huber and Dickinson (15) & $\cdot / r-r / \Delta$ & $1 / \mathrm{Vr}$ & ارتفاع ذخيره مناطق نفوذنإيذير(mm) \\
\hline Tsihrintzis and Hamid (26) & $\Gamma / \omega-\omega / \Lambda$ & $r / \Lambda 1$ & ارتفاع ذخيره مناطق نفوذيذير(mm) \\
\hline Huber and Dickinson (15) & $\Delta-r$. & 19 & درصد مناطق نفوذنايذير بدون ذخير \\
\hline
\end{tabular}

تهيه شد براى اين منظور از دادههاى بارش ايستخاه

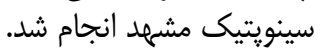

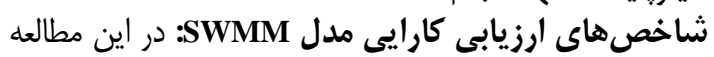

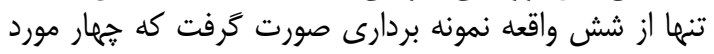

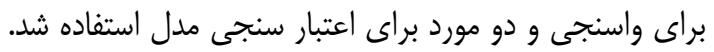

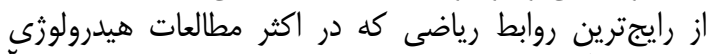

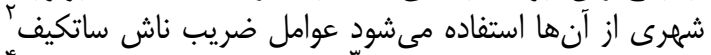

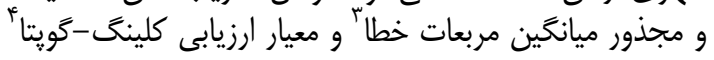

بارش طرح: براى مشخص كردن بارندگى طرح لازم است

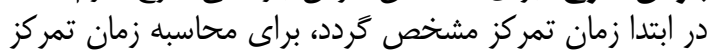

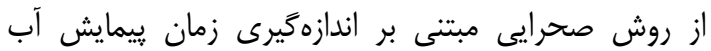

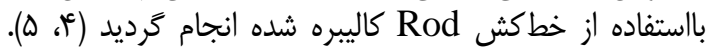

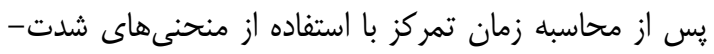

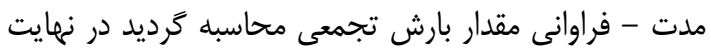

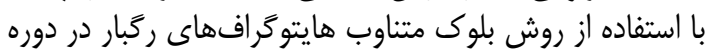

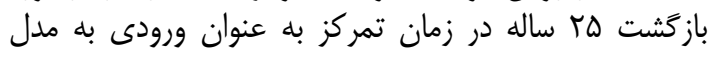


$|4|$

$$
K G E=\sqrt{(r-1)^{r}+(\alpha-1)^{r}+(\beta-1)^{r}}
$$

در فرمول مذكور r ضريب همبستخى بين دادههاى

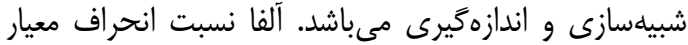

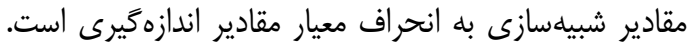

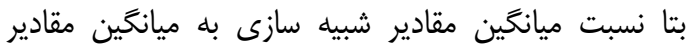

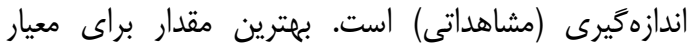

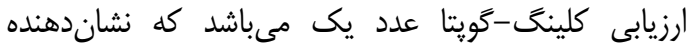

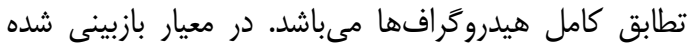

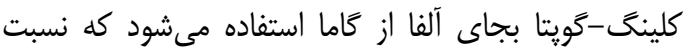
ضريب تغييرات مقادير شبيه سازى به ضريبا لفاي تغييرات مقادير

مشاهداتى مىباشد (IV) - (IV).

\section{نتايج و بحث}

با توجه به رشد سريع شهرها در ايران، مشكلاتى از جمله

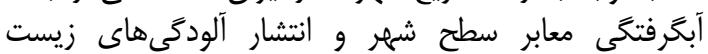

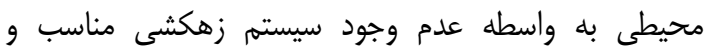

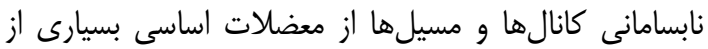

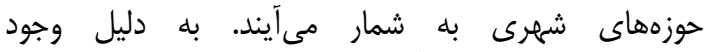
ييجيدگ

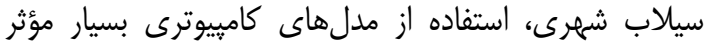

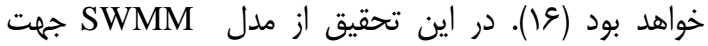

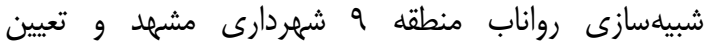

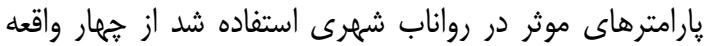

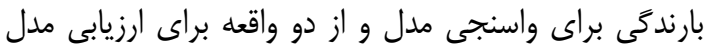

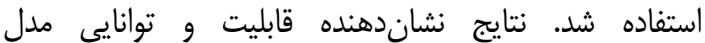
SWMM

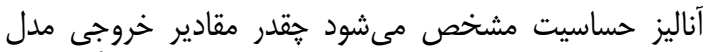

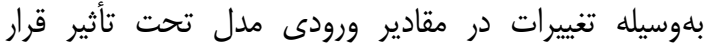

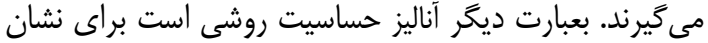

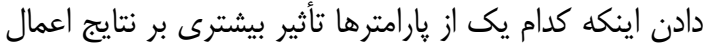

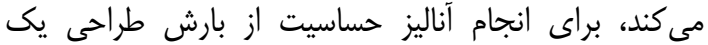

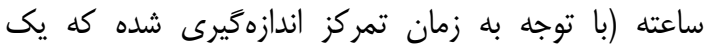

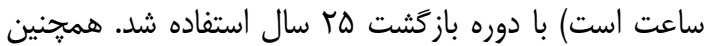

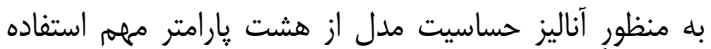

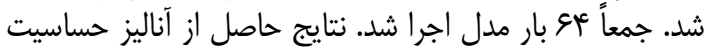

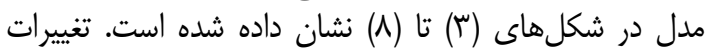

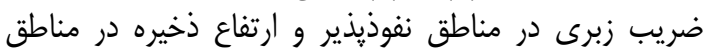
نفوذيذير روى دبى اوج تأثير معنى دارى نفير نشان ندادي
يثزوهشنامه مديريت حوزه آبخيز سال نهم/ شماره M / ياييز و زمستان Vوسا

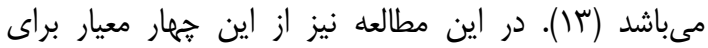
بررسى صحت واسنجى و اعتبار سنجى مدل استفاده كرديد.

$N S=1-\frac{\sum_{i=1}^{n}\left(Q_{s i m}-Q_{o b s}\right)^{2}}{\sum_{i=1}^{n}\left(Q_{o b s}-Q_{a v}\right)^{2}}$

$R M S E=\sqrt{\frac{1}{n} \sum_{i=1}^{n}\left(Q_{\text {sim }}-Q_{o b s}\right)^{2}}$

BIAS \% $=\frac{\sum_{i=1}^{n}(\mathrm{Qsim}-\mathrm{Qobs})^{r}}{\sum_{i}^{n} \text { Qobs }}$

در اينجا Qsim: دبى شبيهسازى شده و Qobs: دبى : دمانى مشاهداتى

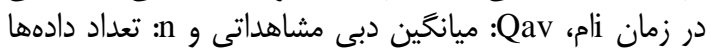

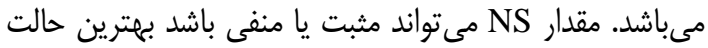

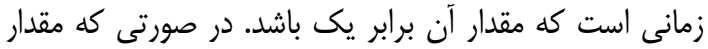

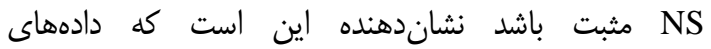
شبيهسازى شده بهتر از ميانخين دادههاى مشاهداتى است است و واندان

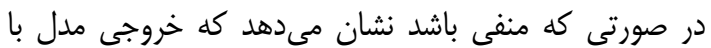

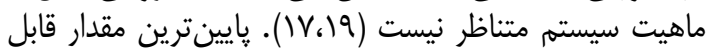

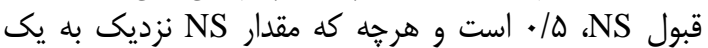

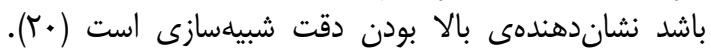

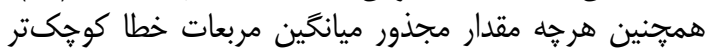

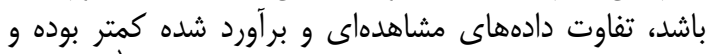

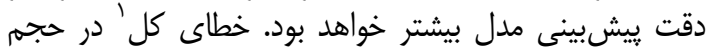

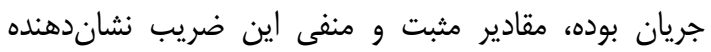

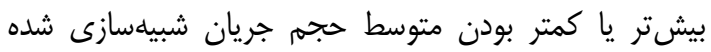

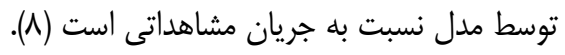
معيار ارزيابى كلينَّ-توريتا

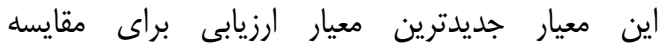

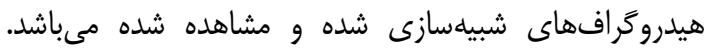

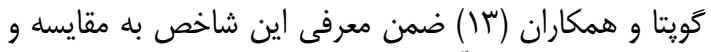

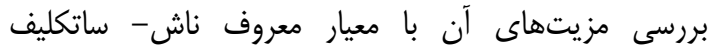

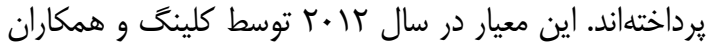

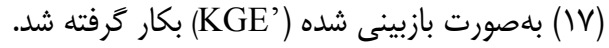




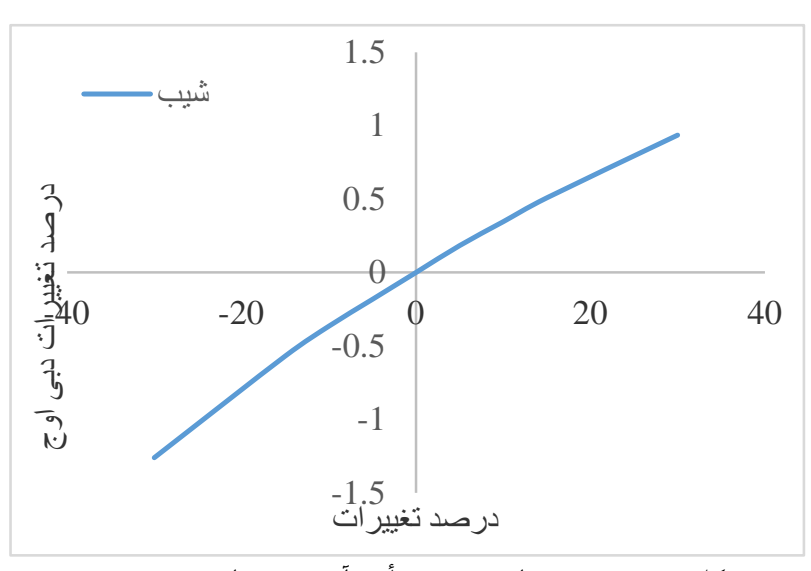

شكل ع- درصد تغييرات شيب و تأثير آن بر دبى اوج بر حسب درصد

Figure 4. The Efective of the SlopeVariation Precentage on the Peak flow

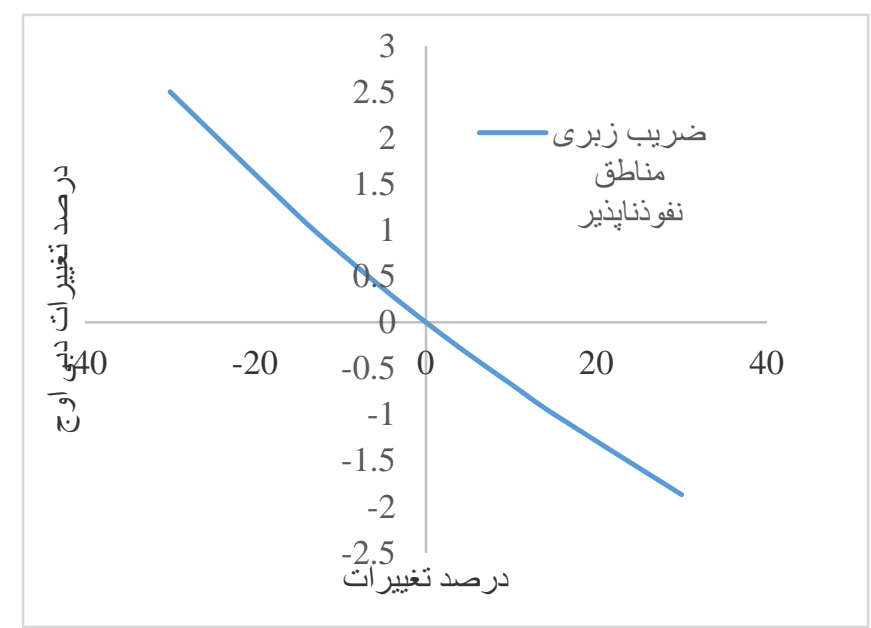

شكل צ- درصد تغييرات ضريب زبرى مانينگ در مناطق نفوذنايذير و تأثير آن بر دبى حرى اوج بر حسب درو مانيند

Figure 6. The Efective of theManning roughness coefficient Variation Precentage on the Peak flow

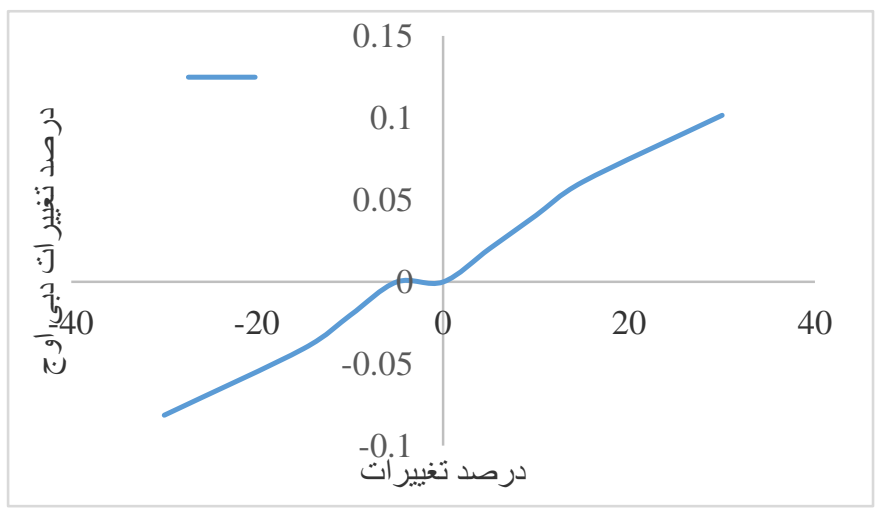

شكل ^- درصد تغييرات مناطق نفوذنايذير بدون ذخيره سطحى و تأثير آن بر دبى اوج بر حسب درصد

Figure 8. The Efective of theimpermeable areas without surface storageVariation Precentage on the Peak flow

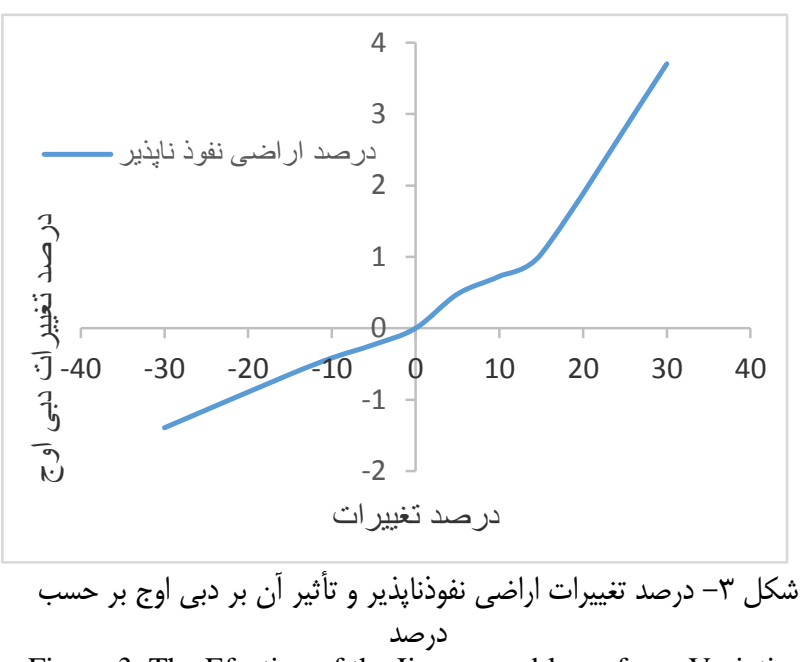

Figure 3. The Efective of the Iimpermeable surfaces Variation Precentage on the Peak flow

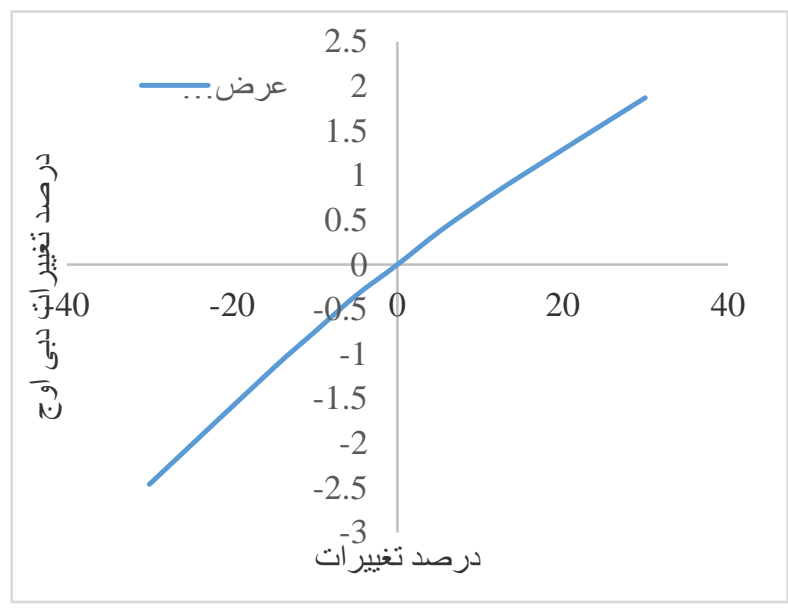

شكل ه- درصد تغييرات عرض معادل و تأثير آن بر دبى اوج بر حسب درصد Figure 5. The Efective of theEquivalent width Variation Precentage on the Peak flow

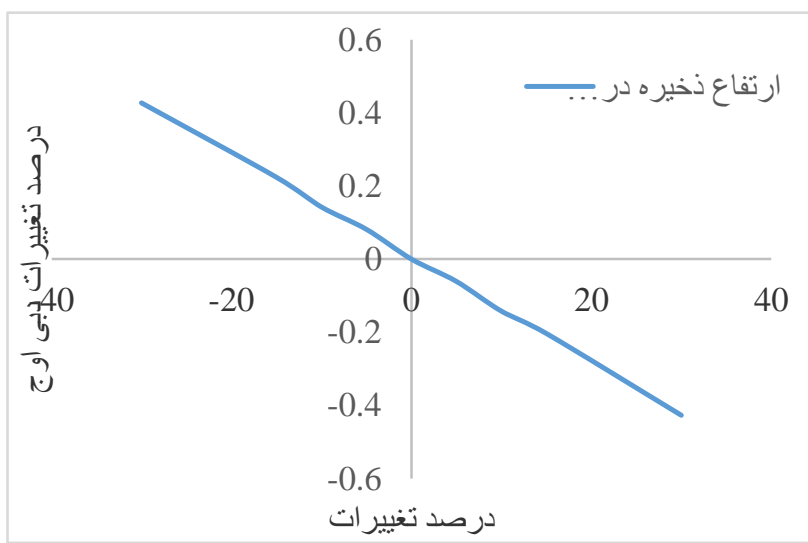

شكل V- درصد تغييرات ارتفاع ذخيره در مناطق نفوذنايذير و تأثير آن بر دبى درصئ

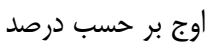

Figure 7. The Efective of the height of storage in impermeable areas Variation Precentage on the Peak flow 
نفوذيذير، شيب زيرحوزه و درصد مناطق بدون ذخيره سطحى)

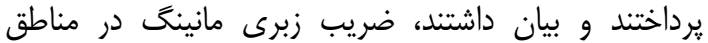

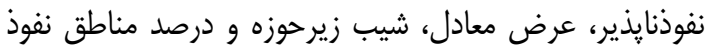

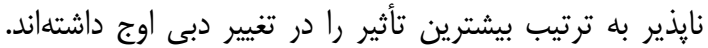

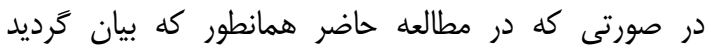

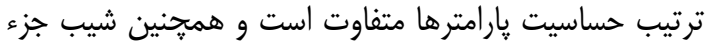

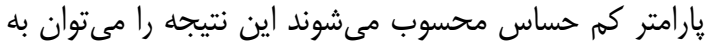

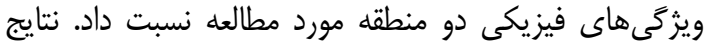

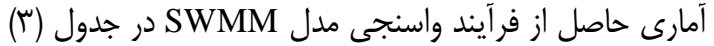

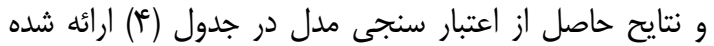

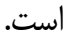

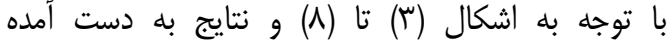

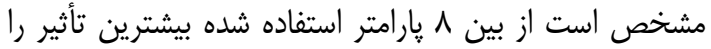

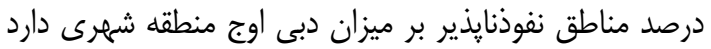

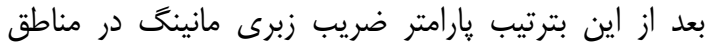

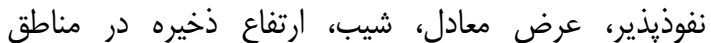

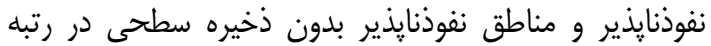

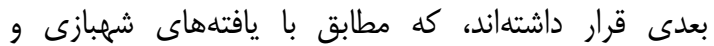

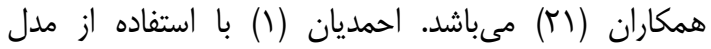

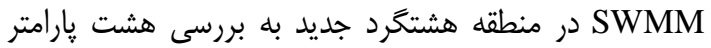

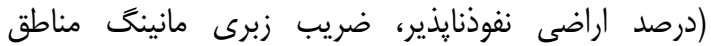

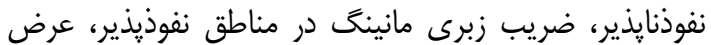
معادل، ارتفاع ذخيره مناطق نفوذنايذير، ارتفاع ذخيره مناطق نفرذ عرضئ

Table 3. The SWMM Model Calibration Results

جدول ب- نتايج واسنجى مدل SWMM

\begin{tabular}{|c|c|c|c|c|}
\hline KGE & BIAS \% & RMSE & معيار Nash & تاريخ بارندگى \\
\hline$\cdot / \mathrm{V} 9$ & $-19 / V^{\mu}$ &.$/ 8$ & $\cdot / \wedge \Delta$ & $1 \% q \mu / 1 \cdot / r$. \\
\hline - /AD & $N / D F$ &.$/ 9 \Delta$ & . /AV & qא/1ו/א \\
\hline . Vq & $-r \Delta / \Delta$ & $\cdot|\Delta|$ & $\cdot / \Lambda$ & \\
\hline.$|9|$ & $-1 \Gamma / \Delta$ &.$/ 91$ & س سوן. & Q \\
\hline
\end{tabular}

Table 4. The SWMM Model Evaluation Results

جدول ع- نتايج ارزيابى مدل SWMM

\begin{tabular}{|c|c|c|c|c|}
\hline KGE & BIAS \% & RMSE & معيار Nash & تاريخ بارندگى \\
\hline$\cdot / \mathrm{WV}$ & $r I / 9 \Delta$ &.$|9|$ &.$/ 8$ & $1 \% q 4 / 1 / V$ \\
\hline$\cdot / V^{e}$ & T/א/T & $1 / 14$ &.$|9|$ & $1494 / 1 / 11$ \\
\hline
\end{tabular}

SWMM

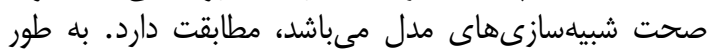

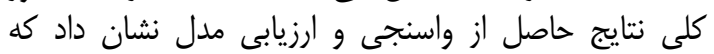

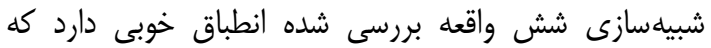

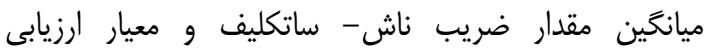

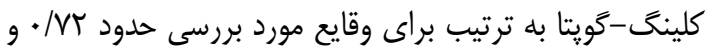

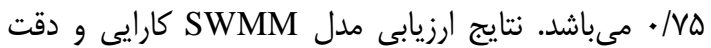

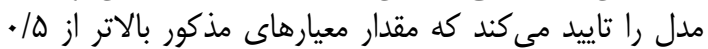

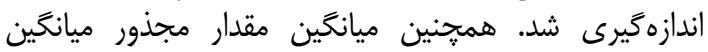

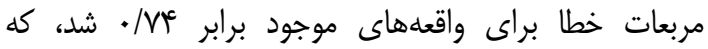

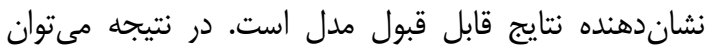

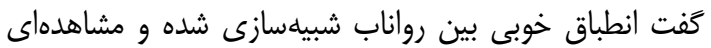

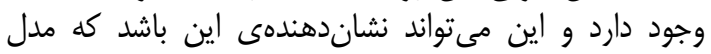

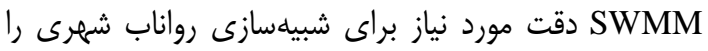

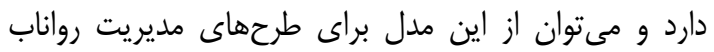

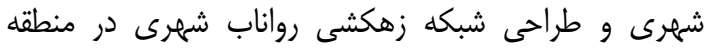
مورد مطالعه استفاده نمود كه با يافته هاى زيكاى كريمى و همكاران و بديعىزاده و همكاران (ع) مود) مطابقت دارد.
نتايج حاصل از واسنجى مدل نشان داد كه شبيهسازى دبى دادي

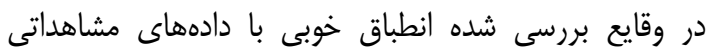

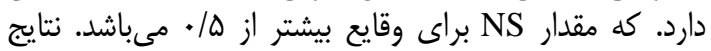

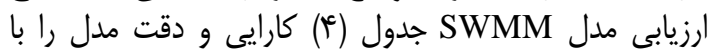

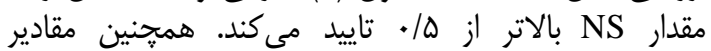
RMSE

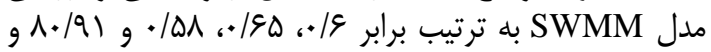

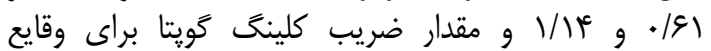
شبيهسازى حاصل از واسنجى و ارزيابى مدل SWMM به كلئ

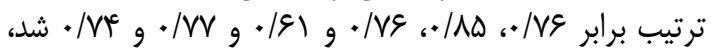

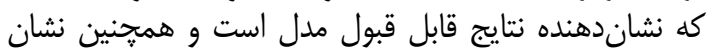

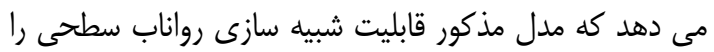

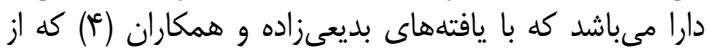

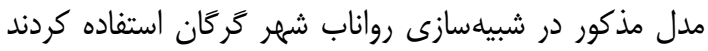

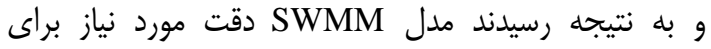

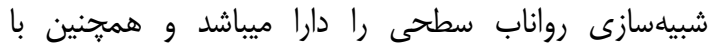

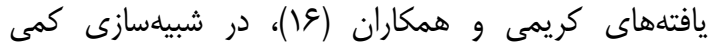

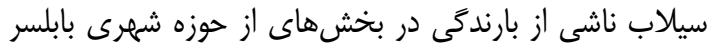

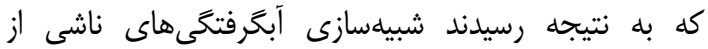

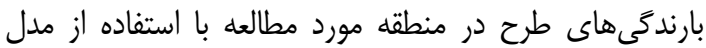


1. Ahmadian, M. 2012. Evaluation of urban runoff by SWMM model to reduce flood Hazard (Hashgrd New Town). Master's thesis, Islamic Azad University Science and Research, Tehran, Iran, 150 pp (In Persian).

2. Ainluo, F. 2014. The effect of land use changes and urban development on runoff (Case Study: Zanjan City). Master's thesis, Natural Resources Department, Tehran University, Tehran, Iran, 180 pp (In Persian).

3. Akart, J. 2005. Applications of Gvatrnry Geological. Department of publications (SID), First Edition, Tehran, $466 \mathrm{pp}$ (In Persian).

4. Badeiizadeh, S., A.R. Bahremand, A.A. Dehghani and N. Nora. 2015. Surface runoff simulation through Urban flood management to Use SWMM model in Gorgan City, Golestan province, Journal of Soil and Water Conservation, twenty-second volume, the fourth number, 1-16 pp (In Persian).

5. Badeiizadeh, S., A.R. Bahremand, A.A. Dehghani and N. Nora. 2016. Calibration and Evaluation of the SWMM Hydrologic-Hydraulic Model to Runoff Simulate (Case Study: Gorgan). Journal of Watershed Management Research, 17(14): 1-10 (In Persian).

6. Chen, J.A.A., L.D Hill and A. Urbano. 2009. GIS-based model for urban flood inundation: Journal of Hydrology, 373: 184-192.

7. Croke, B.F.W., F. Andrews, J. Spate and S.M. Cuddy. 2005. IHACRES User Guide.

8. Dongquan, Z., C. Jining, W. Haozheng, T. Qingyuan, C. Shangbing and S. Zheng. 2009. GIS-based urban rainfall-runoff modeling using an automatic catchment-discretization approach, (case study in Macau). Environ Earth Science, 59: 465-472.

9. Fewtrell, T.J., A. Duncan, C.C. Sampson, J.C. Neal and P.D. Bates. 2011. Benchmarking urban flood models of varying complexity and scale using high resolution terrestrial LIDAR data Original .Research Physics and Chemistry of the Earth, Parts A/B/C, 36(7-8): 281-291.

10. Ghahrodi Tali, M. 2012.The Lout plain railway lines vulnerability of in againest the flood. Journal of geography and environmental hazards, 1(2): 1-18 (In Persian).

11. Ghasemi, S. and M. Maghrebi. 2015. Delav Ponds as solution for development and urban Sustainable management. Iranian Journal of Rainwater Catchment Systems, 3(6): 14-1 (In Persian).

12. Gironas, J., L.A. Roesner, L.A. Rossman and j. Davis. 2010. A new applications manual for the Storm Water Management Model (SWMM). Environmental Modelling and Software, 25: 813-814.

13. Gupta. H.V., H. Kling, K. Koray, Y. Guillermo and F. Martinez. 2009. Decomposition of the mean squared error and NSE performance criteria: Implications for improving hydrological modelling. Journal of Hydrology, 377(1-2): 80-91.

14. Hosein zadeh, S.R. and M. Jahadi Toroughi. 2007. The Mashhad city development effects of natural drainage pattern and urban flooding intensify. Journal of Geographic studies, 61: 145-159 (In Persian).

15. Huber, W.C. and R.E. Dickinson. 1992. Storm water management model user's manual, version 4. Environmental Protection Agency, Georgia.

16. Karimi, V.A., K. Solimani, M. Habibnejad Roshan and K. Shahedi. 2015. Simulation of Flow in Open \& Closed Conduits by EPA-SWMM Model (Case Study: Babolsar Urban Watershed). Journal of Watershed Management, 11: 162-170 (In Persian).

17. Kling, H., M. Fuchs and M. Paulin. 2012. Runoff conditions in the upper Danube basin under an ensemble of climate change scenarios. Journal of Hydrology, 424-425(6): 264-277.

18. Nash, J.E. and J.V. Sutcliffe. 1970. River flow forecasting though conceptual models. Part 1-A discussion of principles. Journal of. Hydrology, 10: 282-290. Technical Report, 2005/19.

19. Safari, A. and F. Sasanpor. 2011. Urban areas vulnerability assessment against flood hazard to using GIS and fuzzy logic (Case Study: Tehran3 Zone). Journal of Geographical Sciences Applied Research, 11(20): 129-150 (In Persian).

20. Shahbazi, A. 2012. Urban runoff management to reduce Hazard by SWMM Model. Master's thesis, Department of Natural Resources, Tehran University, Tehran, Iran (In Persian).

21. Shahbazi, A., Sh. Khalighi Sigarodi, A. Malkian and A. Salagagheh. 2013. Input parameters sensitivity analysis of SWMM Urban Ronof management Model (Case Study: City Mahdasht) Journal of Research and development.Journals, 30(1): $67-75$ (In Persian).

22. Santhi, C., J.G. Arnold, J.R. Williams. W.A. Dugas, R. Srinivasan and L.M. Hauck. 2001. Validation of the SWAT model on a large river basin with point and nonpoint sources. J Am Water Resources Association, 37: 1169-1188.

23. Sourisseau, S.A., S.F. Basser and T. Perie. 2007. Calibration, validation and sensitivity analysis of an ecosystem model applied to artificial streams. Water Research, 42(4-5): 1167-1181.

24. Temprano, J., O. Arango, J. Cagiao, J. Suarez and I. Tejero. 2006. Storm water quality calibration by SWMM: a case study in Northern Spain. Water SA, 32(1): 55-63.

25. Tingsanchali, T. 2012. Urban flood disaster management Sciverse Science Direct. Procedia Engineering, 32(2012): 25-37.

26. Tsihrintzis, V. and R. Hamid. 1998. Runoff quality prediction from small urban catchments using SWMM. Hydrol Process, 12(2): 311-329. 


\title{
Determination of the Most Important Parameters Affecting the Urban Runoff using SWMM Model (Case Study: Mashhad City, District 9)
}

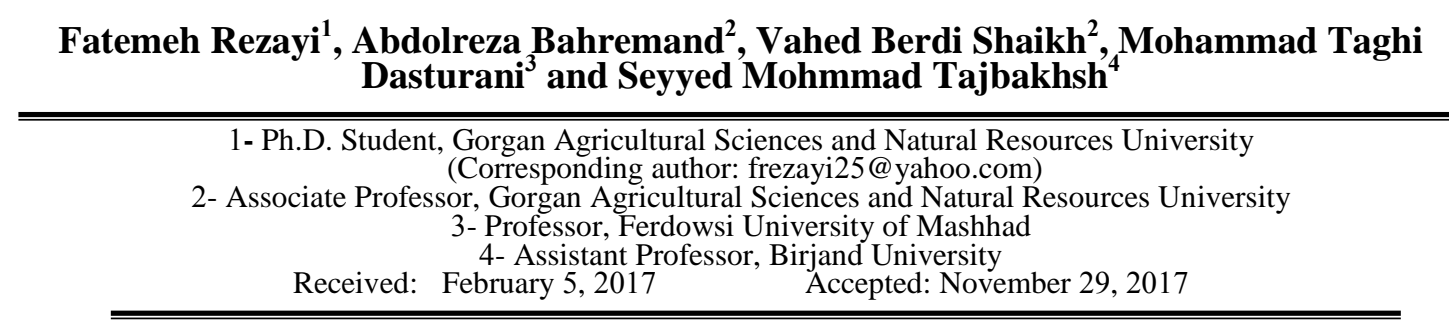

\begin{abstract}
Due to the rapid urbanization in Iran, different issues have emerged in its major cities such as street flooding, dispersal of dangerous chemicals and flood-related risks due to the lack of a proper drainage network and disorders in the flood channels; and, Mashhad is not exempt from these issues. The aim of this study is to determine the most important parameters affecting (area of impermeable surfaces has the highest impact, followed by the Manning roughness coefficient in permeable areas, the equivalent width, slope, height of storage in impermeable areas, and impermeable areas without surface storage) runoff generation in District 9 of Mashhad city and to evaluate the performance of the SWMM model. The SWMM model was used to simulate runoff and identify critical areas. In order to determine the duration of the design storm, time of concentration was measured and used as a surrogate. Sensitivity analysis showed that among the eight considered parameters, area of impermeable surfaces has the highest impact, followed by the Manning roughness coefficient in permeable areas, the equivalent width, slope, height of storage in impermeable areas, and impermeable areas without surface storage. The model calibration results showed a good agreement between the simulations of the four incidents with a NS higher than 0.5. The obtained NS confirms the SWMM model's performance and accuracy. The RMSE was measured $0.6,0.65,0.58$ and 0.91 respectively for the incidents dated $2015 / 1 / 10,2015 / 2 / 15,2015 / 2 / 21$ and $2015 / 3 / 6$, as well as 0.61 and 1.14 for the incidents dated 1394/1/7 and 1394/1/11, which suggest an acceptable model performance. Given the results, there is a good agreement between the simulated and actual runoff volumes which is an indication of the good performance of the SWMM model in predicting urban flood and the model could then be used in urban flood management projects and drainage network planning in Mashhad.
\end{abstract}

Keywords: Urban runoff, SWMM model, Sensitivity analysis, Calibration, Validation, Time of Concentrati 